\title{
CHEMOSPHERE
}

PERGAMON

\section{Effect of organic acids on adsorption and desorption of rare earth elements}

\author{
Xiao-quan Shan *, Jun Lian, Bei Wen \\ Research Center for Eco-Environmental Sciences, Chinese Academy of Sciences, P.O. Box 2871, Beijing 100085, China
}

Received 28 June 2001; received in revised form 7 December 2001; accepted 16 January 2002

\begin{abstract}
Effect of citric, malic, tartaric and acetic acids on adsorption of $\mathrm{La}, \mathrm{Ce}, \mathrm{Pr}$ and $\mathrm{Nd}$ by and desorption from four typical Chinese soils was studied. Generally, adsorption capacities of rare earth elements (REEs) were significantly correlated with the cation exchange capacity (CEC) of soils. In the presence of acetic acids adsorption of REEs was similar to that in the presence of $\mathrm{Ca}\left(\mathrm{NO}_{3}\right)_{2}$. However, in the presence of citric, malic and tartaric acids adsorption of REEs by Heilongjiang, Zhejiang and Guangdong soils decreased to varying extents if compared with that in the presence of nitrate and acetic acid. The significance of suppression followed the order of citric acid $>$ malic acid $>$ tartaric acid > acetic acid, which was consistent with the order of stability of complexes of REEs with these organic acids. However, the adsorption increased with increasing equilibrium solution $\mathrm{pH}$. For Jiangxi soil with low soil $\mathrm{pH}$, CEC and organic matter these organic acids exerted an even more serious suppression effect on the adsorption of REEs. Another feature of the relationship between the adsorption of REEs and equilibrium solution $\mathrm{pH}$ was that the adsorption of REEs decreased with increase of $\mathrm{pH}$ from 2 to 4.5 and then slightly increased with further increase of $\mathrm{pH}$. Desorption of REEs varied with soils and with organic acids as well. REEs were released easily from Heilongjiang, Zhejiang and Guangdong soils in the presence of organic acid. Generally, desorption of REEs decreased with increasing equilibrium solution $\mathrm{pH}$. Effect of organic acids on desorption of REEs from Jiangxi soil was more complicated. In the presence of citric and malic acids no decrement and/or slight increase in desorption of REEs were observed over the equilibrium solution $\mathrm{pH}$ from 3 to 6.5. The reasons for this were ascribed to the strong complexing capacity of citric and malic acids and low soil pH, CEC and organic matter of Jiangxi soil. (c) 2002 Published by Elsevier Science Ltd.
\end{abstract}

Keywords: Adsorption; Desorption; Organic acids; Rare earth elements

\section{Introduction}

In recent years, more and more rare earth elements (REEs) enter the environment through various pathways because of the rapid increase of the exploitation of REE resources and its applications to modern industry and daily life (Volokh et al., 1990). Moreover, millions of tons of fertilizers containing REEs are used world-

\footnotetext{
* Corresponding author. Tel.: +86-10-6292-3560; fax: +8610-6292-3563.

E-mail address: xiaoquan@mail.rcees.ac.cn (X.-q. Shan).
}

wide for increasing agricultural productivity (Bremmer, 1994). In China, the fertilizer containing REEs for agriculture use was estimated to cover $(16-20) \times 10^{6}$ ha in 1995 (Tu et al., 1994). It has been forecasted that the agricultural usage of the fertilizers containing REEs might result in environmental problems in the next few decades (Volokh et al., 1990). REEs from anthropogenic sources usually get into the environment in biologically available forms, which are of particular concern because they may dislocate the balance of the biogeochemical cycle of these species. A comprehensive study is needed to determine the behavior of REEs in different soils. 
It is well established that the bioavailability, and potential toxicity or deficiency of trace metal ions in soils depend on their concentrations in the soil solution and on the soil's ability to release trace metal ions from the soil phase to replenish those removed from solutions by plants (Backes et al., 1995). The concentrations of metals in soil solutions are most likely to be controlled by sorption-desorption reactions (Hogg et al., 1993). From this point of view, study on the sorptiondesorption reactions of REEs is important. Jones (1997) reported that adsorption of $\mathrm{La}, \mathrm{Y}, \mathrm{Pr}$ and $\mathrm{Gd}$ depended on soil $\mathrm{pH}$ and cation exchange capacity (CEC). The adsorption appeared to conform well to the single Langmuir equation. Equilibrium release experiments (Cao et al., 2001) demonstrated that the release of La, $\mathrm{Ce}, \mathrm{Gd}$ and $\mathrm{Y}$ increased with decreasing $\mathrm{pH}$ or Eh. It was also reported that the release of REEs were correlated with the release of $\mathrm{Fe}$ and $\mathrm{Mn}$, suggesting that the release of REEs originated from dissolution of $\mathrm{Fe}-\mathrm{Mn}$ oxyhydroxides under the reduced and low soil $\mathrm{pH}$ conditions ( $\mathrm{Li}$ et al., 1998). The adsorption of REEs increased with increasing soil pH (Ran and Liu, 1992, 1993). Li et al. (2001) studied the kinetics of adsorption and desorption of Ce(III) on soil using a batch method and isotope ${ }^{141} \mathrm{Ce}$. It was indicated that the Elovich equation proved to fit the data on desorption of Ce(III) from fluvoaquic and black soils well, while the parabolic-diffusion equation were the best models for red earth and loess soils.

It is well recognized that the rhizosphere is a zone of increased microbial activity and biomass under the influence of the plant roots, which can secret substances such as carbohydrates and low-molecular-weight-organicacids (LMWOAs). In addition, LMWOAs can also be produced due to breakdown of plant residues. Thus, this zone is distinguished from bulk soil by this root influence (Anderson et al., 1993). LMWOAs are involved in many interactions with the physicochemical properties of soils and capable of forming complexes with metal ions (Robert and Berthelin, 1994; Stevenson and Fitch, 1994). Therefore they play an important role in the sorption and desorption processes of heavy metals (Harter, 1983; Bruemmer et al., 1988; Backes et al., 1995). The leaching procedures and bioavailability of heavy metals have also been affected by LMWOAs (Zhang et al., 2000; Wang et al., 2001).

It seems that there is no report in the literature on the effect of LMWOAs on sorption and desorption behavior of REEs. Indeed, such a comprehensive knowledge allows one to predict transformation, bioavailability and mobilization of REEs in soils, thus it helps to predict the long-term effect on the environment. To our knowledge this is the first time to address the effect of LMWOAs such as citric, malic, tartaric and acetic acids on adsorption by and desorption behaviors of REEs from soils.

\section{Materials and methods}

\subsection{Soils and soil characterization}

Four surface soils were collected from Jiangxi and Guangdong Provinces (southern China), Zhejiang Province (eastern China), and Heilongjiang Province (northeastern China). All the soil samples were taken from the surface layer $(0-20 \mathrm{~cm})$ of cultivated soils. The soils were air dried, sieved to pass through a 20-mesh sieve, homogenized, and stored in polyethene bags for the further analysis. Soil $\mathrm{pH}$ values were measured in soil to water ratio of $1: 1(\mathrm{w} / \mathrm{v})$. CECs were determined by the Rhoades' method (1982) and organic matter contents were determined by the Walkley-Black' method (Nelson and Sommers, 1982). Amorphous iron (Fe) and aluminum (Al) oxides were determined by ammonium oxalate extraction (McKeague and Day, 1966). Crystalline $\mathrm{Fe}$ and $\mathrm{Al}$ oxides were determined by the oxalateascorbic acid extraction method of Shuman (1982). These properties of the soils are given in Table 1. Fertilizer containing $\mathrm{La}, 27.4 \%$; $\mathrm{Ce}, 50.8 \%$; $\mathrm{Pr}, 5.4 \%$ and $\mathrm{Nd}, 15.3 \%$ in nitrate form was used as exogenous REEs in this study.

\subsection{Organic acids}

Citric, malic, tartaric and acetic acids were chosen as the representatives of LMWOAs present in the rhizosphere soils. The stability constants of organic acidsREE complexes were different from one to another.

Table 1

Selected properties of studied soils

\begin{tabular}{|c|c|c|c|c|c|c|c|c|}
\hline \multirow[t]{2}{*}{ Sampling site } & \multirow[t]{2}{*}{ Order } & \multirow{2}{*}{$\begin{array}{l}\text { CEC } \\
(\mathrm{cmol} / \mathrm{kg})\end{array}$} & \multirow[t]{2}{*}{$\mathrm{pH}(1: 1)$} & \multirow{2}{*}{$\begin{array}{l}\text { Organic } \\
\text { matter }(\%)\end{array}$} & \multicolumn{2}{|l|}{$\mathrm{Fe}(\%)$} & \multicolumn{2}{|l|}{$\mathrm{Al}(\%)$} \\
\hline & & & & & Crystal. & Amorp. & Crystal. & Amorp. \\
\hline Jiangxi & Ultisol & 14.24 & 4.63 & 1.53 & 3.52 & 0.72 & 1.39 & 0.28 \\
\hline Zhejiang & Ultisol & 19.76 & 7.02 & 3.28 & 2.50 & 0.97 & 1.07 & 0.18 \\
\hline Guangdong & Alfisol & 15.92 & 7.56 & 1.37 & 2.30 & 0.36 & 0.79 & 0.13 \\
\hline Heilongjiang & Mollisol & 21.57 & 6.00 & 5.38 & 2.01 & 0.35 & 1.36 & 0.28 \\
\hline
\end{tabular}




\subsection{Adsorption isotherms}

Adsorption isotherms were performed by batch equilibrium experiments. A portion of $0.500 \mathrm{~g}$ of soils was placed in $40 \mathrm{~mL}$ of polypropylene centrifuge tubes, then $20 \mathrm{~mL}$ of background electrolyte solution of 0.01 mol/L of $\mathrm{Ca}\left(\mathrm{NO}_{3}\right)_{2}$ containing different amounts of REE fertilizer were added depending on the adsorption capacity of individual soil. $\mathrm{Ca}\left(\mathrm{NO}_{3}\right)_{2}$ was used as supporting electrolyte to eliminate non-specific adsorption of REEs since low affinity sites would be saturated by calcium ions. The mixtures were shaken by end-over-end for $24 \mathrm{~h}$, then centrifuged for $0.5 \mathrm{~h}$ at $6000 \mathrm{rpm}$, and finally filtered through a $0.45 \mu \mathrm{m}$ of cellulose nitrate membrane. Adsorbed amounts of REEs were calculated from the difference between the amounts added to and the amounts remained in the solution.

\subsection{Effect of organic ligands and equilibrium solution $p H$ on adsorption of REEs}

Effect of organic ligands and equilibrium solution $\mathrm{pH}$ on the adsorption of REEs by Heilongjiang and Jiangxi soils was investigated. Different organic acids were prepared at their final concentration of $0.01 \mathrm{~mol} / \mathrm{L}$ in background electrolyte of $0.01 \mathrm{~mol} / \mathrm{L} \mathrm{Ca}\left(\mathrm{NO}_{3}\right)_{2}$ and their $\mathrm{pH}$ values were adjusted with dilute $\mathrm{Ca}(\mathrm{OH})_{2}$ in the range of 2.6-7.8. After $\mathrm{pH}$ adjusting, certain amount of REEs was added to make the final concentrations of REEs in one supporting electrolyte solutions to be 2.91, $5.39,0.58$ and $1.62 \mu \mathrm{g} / \mathrm{mL}$ of $\mathrm{La}, \mathrm{Ce}, \mathrm{Pr}$ and $\mathrm{Nd}$, respectively. In another supporting electrolyte the concentrations of $\mathrm{La}, \mathrm{Ce}, \mathrm{Pr}$ and $\mathrm{Nd}$ were defined as 10.55 , 26.98, 2.29 and $8.12 \mu \mathrm{g} / \mathrm{mL}$, respectively. A portion of $0.500 \mathrm{~g}$ of soil samples were equilibrated with $20 \mathrm{~mL}$ of $0.01 \mathrm{~mol} / \mathrm{L}$ of organic acid $-0.01 \mathrm{~mol} / \mathrm{L}$ of $\mathrm{Ca}\left(\mathrm{NO}_{3}\right)_{2}$ solutions containing REEs at the above mentioned concentration levels under the conditions of continuous shaking for $24 \mathrm{~h}$. Then, the samples were centrifuged at 6000 for $0.5 \mathrm{~h}$, the $\mathrm{pH}$ values of equilibration solutions were determined again, and the concentrations of REEs in the equilibration solutions remained were determined as well by using inductively coupled plasma mass spectrometry (ICP-MS) (Wen et al., 1999).

\subsection{Effect of organic ligands and $p H$ on extractable REES}

Subsamples of $100 \mathrm{~g}$ of soils were mixed with $100 \mathrm{~mL}$ of $200 \mu \mathrm{g} / \mathrm{mL}$ of REE fertilizer, and shaken for $48 \mathrm{~h}$. Then, the soils were incubated for three weeks, during this process they were periodically weighed and any weight loss was made up with regular addition of distilled, deionized water. After the soils were incubated for various periods, the supernatant was removed and the concentrations of REEs remained in the supernatants were determined. Then, the soils were air dried, groun- ded to pass through a 20-mesh sieve, homogenized, and stored in polyethene bags. Duplicate $0.500 \mathrm{~g}$ samples of the incubated air-dried soils were placed in polypropylene centrifuge tubes and $20 \mathrm{~mL}$ of $0.01 \mathrm{~mol} / \mathrm{L}$ organic acids were added. The samples were shaken on an endover-end shaker for $16 \mathrm{~h}$, centrifuged for $0.5 \mathrm{~h}$ at 6000 rpm, and filtered through a $0.45 \mu \mathrm{m}$ membrane. After filtration, the concentrations of REEs in the filtrates were determined by ICP-MS. In addition, $\mathrm{pH}$ values of the filtrates were also measured. Since the $\mathrm{p} K_{\mathrm{a}} \mathrm{s}$ of the organic acids vary considerably, the nature of organic acids is different at any given $\mathrm{pH}$ with different organic acids. REEs adsorbed in the incubated soils for three weeks were extracted with various organic acids at the $\mathrm{pH}$ range between 3.1 and 7.0. The $\mathrm{pH}$ values of all organic acids were monitored, and $\mathrm{pH}$ variations were only $0.1-0.4$ units before and after extraction. REEs in the extracts were determined by ICP-MS.

\subsection{Determination of REES}

REE concentrations in the extracts were determined by ICP-MS. The instrumental operation parameters were optimized. Indium was added as an internal standard to monitor matrix effects and signal drift. The details were reported previously by Wen et al. (1999).

\section{Results and discussion}

\subsection{Adsorption isotherms}

Owing to the similar physicochemical properties of REEs, adsorption and desorption behaviors of REEs were somewhat alike (Brown et al., 1990). Therefore, only the adsorption isotherms of La were schematically shown in Fig. 1. As can be seen that adsorption amounts of La by various soils increased with increasing concentration of $\mathrm{La}$ in the equilibrium solutions. Two isotherm models were used to described adsorption behaviors of REEs by soils. They are the Langmuir equation: $x / m=K_{1} K_{2} C /\left(1+K_{1} C\right)$ and the Freundlich equation: $x / m=K C^{1 / n}$, where $x / m$ is the adsorption amount of La by soil $(\mu \mathrm{g} / \mathrm{g}) ; C$ is the La concentration remained in the equilibrium solution $(\mu \mathrm{g} / \mathrm{mL}) ; K_{1}, K$ and $n$ are parameters (constants) for the equations. $K_{2}$ is the maximum adsorption capacity of $\mathrm{La}(\mathrm{mg} / \mathrm{g})$. The results showed that the adsorption of La corresponded to the two equations well $\left(\gamma^{2}>0.91, p<0.05\right)$. Maximum adsorption capacities of REEs for all soils were shown in Table 2, together with the relationship between the maximum adsorption capacity and soil characteristics. As it was shown that Heilongjiang soil had the highest adsorption capacity, while Jiangxi soil had the least. A significant relationship between maximum adsorption capacity of REEs and CEC of soils was found, with the 


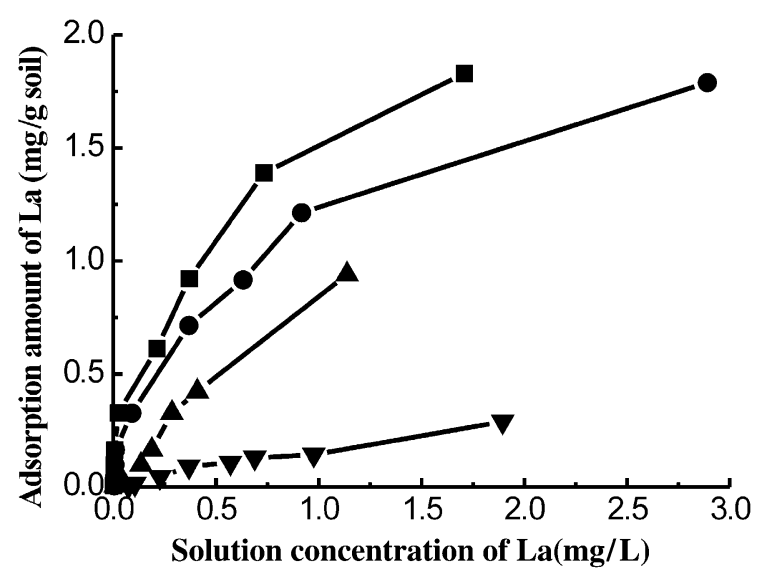

Fig. 1. Adsorption of La in soils in the presence of $0.01 \mathrm{~mol} / \mathrm{L}$ $\mathrm{Ca}\left(\mathrm{NO}_{3}\right)_{2}$ Heilongjiang soil (ם); Zhejiang soil (•); Guangdong soil (ム); Jiangxi soil ( $)$.

range of $\gamma$ from 0.939 to 0.989 . However, only a poor relationship between maximum adsorption capacity and organic matter or total amounts of $\mathrm{Al}_{2} \mathrm{O}_{3}$ and $\mathrm{Fe}_{2} \mathrm{O}_{3}$ existed.

\subsection{Effect of organic acids and $\mathrm{pH}$ on adsorption of REEs by soils}

The concentrations of LMWOAs were reported to be in the range of $10^{-7}-10^{-4} \mathrm{~mol} / \mathrm{L}$ in the soil pore solutions, even higher in the rhizosphere soils (Stevenson, 1994; Krishnamurti et al., 1997). The concentrations of $1-10 \mathrm{mM}$ of organic acids were used in the sorption and desorption of cadmium (Krishnamurti et al., 1997; Naidu and Harter, 1998). Therefore, a concentration of $10^{-2} \mathrm{~mol} / \mathrm{L}$ of LMWOAs was chosen in this study to simulate the adsorption of REEs by and desorption from the rhizosphere soils.

The effect of different organic acids and equilibrium solution $\mathrm{pH}$ on adsorption of REEs at its various concentration levels by Heilongjiang and Jiangxi soils were shown in Figs. 2 and 3, respectively. Compared the profiles of the left side with that of the right side (Figs. 2 and 3), one may concluded that when higher amounts of REEs added, total adsorbed REEs increased while adsorption percent decreased. For Heilongjiang soil, in the presence of both $\mathrm{Ca}\left(\mathrm{NO}_{3}\right)_{2}$ and acetic acid, near $100 \%$ of REEs can be sorbed in the experimental $\mathrm{pH}$ range. It seemed that $\mathrm{pH}$ did not affect the adsorption behavior of REEs. However, for Jiangxi soil, in the presence of $\mathrm{Ca}\left(\mathrm{NO}_{3}\right)_{2}$, with the $\mathrm{pH}$ increase, the sorbed REEs increased from $40 \%$ to more than $90 \%$. It was indicated that the affinity between Heilongjiang soil and REEs was larger than that between Jiangxi soil and REEs. In the presence of citric, malic and tartaric acids, adsorption of REEs for both soils decreased obviously. In the mean time, with the $\mathrm{pH}$ decreased, the amount of adsorption decrease gradually from Heilongjiang soil. This pH-dependent behavior of heavy metal sorption is generally recognized (Tiller et al., 1979; Naidu and Harter, 1998). Effect of different organic acid on the decrease of REEs adsorption was dissimilar. Among the organic acids studied, effect of citric acid on the decrease of REE adsorption is the most significant, while that of acetic acid is the least. For example, at pH 5 in Heilongjiang soil, the decrease in La adsorption is $20 \%, 24 \%$ and $48 \%$ in the presence of tartaric, malic and citric acid, respectively (Fig. 2), while almost no decrement of adsorption occurred when acetic acid was added. The reduction of adsorption of REEs followed the orders: citric acid $>$ malic acid $>$ tartaric acid $>$ acetic acid. This order is in consist with the stability constants of REEs with these organic ligands $\left(\log K_{1}\right.$ for four Laorganic acid complexes, Martell and Smith, 1977), indicating the formation of aqueous REEs-organic ligands complexes is one of the important reasons for the adsorption decrease. In the absence of organic ligands system with only electrostatic attraction and repulsion existing, the adsorption of REEs was a function of soil characteristics, while in the presence of organic ligands, there existed a competitive effect for REEs between soil adsorption sites and aqueous organic ligands. The affinity of organic ligands, which causes the decrement of adsorption, was related to the REEs-organic ligand

Table 2

Maximum adsorption capacity $K_{2}(\mathrm{mg} / \mathrm{g})$ for REEs in four soils and correlation matrix $(\gamma)$ for $K_{2}$ of REEs and CEC, organic matter (OM), total content of $\mathrm{Fe}_{2} \mathrm{O}_{3}$ and $\mathrm{Al}_{2} \mathrm{O}_{3}(\%)$

\begin{tabular}{|c|c|c|c|c|c|c|c|}
\hline \multirow[t]{2}{*}{ Element } & \multicolumn{4}{|l|}{$K_{2}(\mathrm{mg} / \mathrm{g})$} & \multicolumn{3}{|l|}{$\gamma$} \\
\hline & Heilongjiang & Zhejiang & Guangdong & Jiangxi & $\overline{\mathrm{CEC}}$ & $\mathrm{OM}$ & $\begin{array}{l}\mathrm{Fe}_{2} \mathrm{O}_{3} \text { and } \\
\mathrm{Al}_{2} \mathrm{O}_{3}\end{array}$ \\
\hline $\mathrm{La}$ & 2.106 & 2.039 & 1.249 & 0.191 & $0.939^{\mathrm{a}}$ & 0.774 & -0.779 \\
\hline $\mathrm{Ce}$ & 4.338 & 3.963 & 1.465 & 0.382 & $0.989^{b}$ & 0.889 & -0.587 \\
\hline $\operatorname{Pr}$ & 0.467 & 0.405 & 0.137 & 0.046 & $0.981^{\mathrm{b}}$ & 0.876 & -0.554 \\
\hline $\mathrm{Nd}$ & 1.214 & 1.171 & 0.386 & 0.083 & $0.982^{b}$ & 0.873 & -0.537 \\
\hline
\end{tabular}

\footnotetext{
${ }^{a}$ Significance at $10 \%$ level.
}

${ }^{\mathrm{b}}$ Significance at $5 \%$ level. 

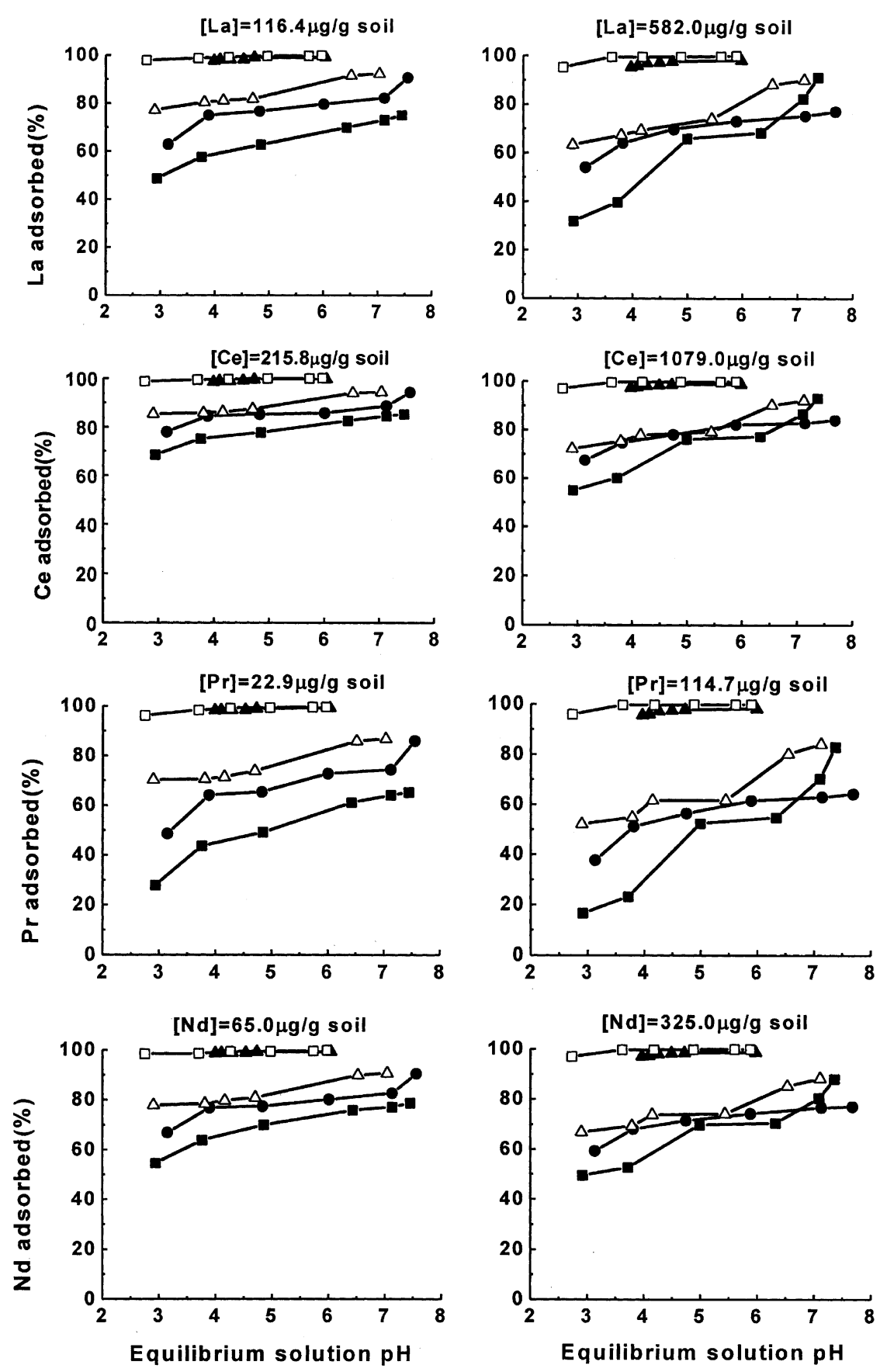

Fig. 2. Effect of organic acids and $\mathrm{pH}$ on adsorption of REEs in Heilongjiang soil, organic acids: citric acid (ם); malic acid (•); tartaric acid $(\triangle)$; acetic acid $(\mathbf{\Lambda})$; nitrate $(\square)$.

stability constants and concentration of organic ligand. Soils are a heterogeneous complex system with organic matter; iron-, aluminum-, and manganese-oxides; clay minerals, and miscellaneous other minerals. Each component of soils exhibits its different influence on REEs entering the soil, precisely quantification of the soil affinity is quite difficult. In many systems, the valence of the adsorbate and adsorbent surface charge influences the heavy metal adsorption strongly (Dalang and Stumm, 1976; Elliott and Huang, 1979). Elliott and 

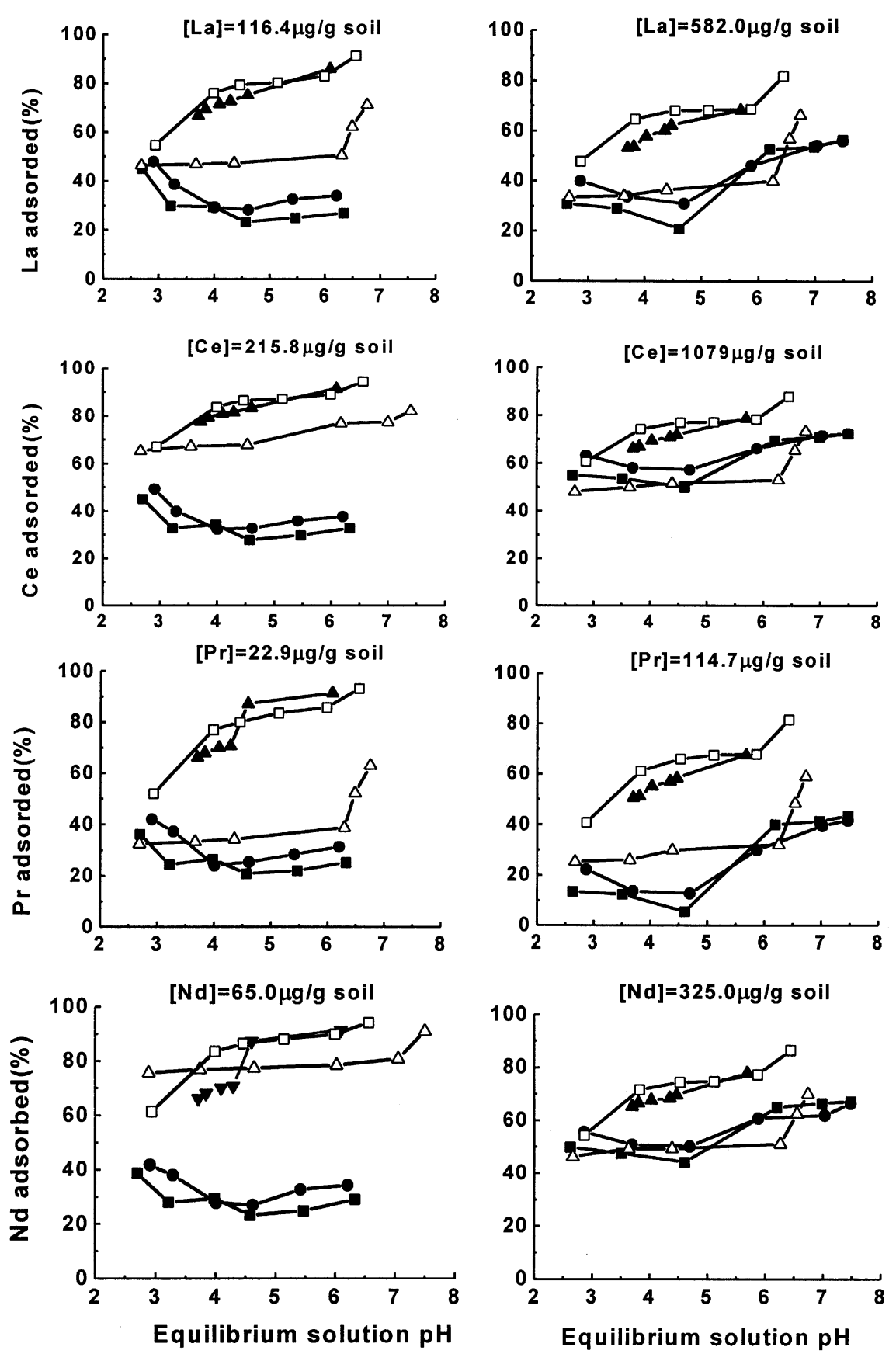

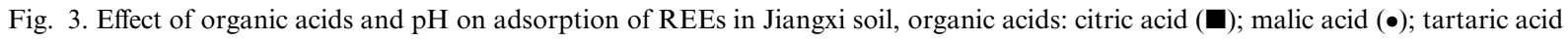
$(\triangle)$; acetic acid $(\mathbf{\Lambda})$; nitrate $(\square)$.

Denneny (1982) determined the $\mathrm{pH}$ of zero net surface charge (zero point of charge, ZPC) in three soils. Their results showed that the $\mathrm{pH}_{\mathrm{zpc}}$ of all the studied soils was low, so the surface charges were therefore electronegative. Thus the electrostatic attraction with the cationic complexes would be expected. Wang et al. (2000) in- vestigated the $\mathrm{pH}$ at the zero point charge using electrophoresis and further calculated the stability constant of metal-sludge complex. Generally, biological and other organic materials have low $\mathrm{pH}_{2 \mathrm{pc}}$ values, while inorganic adsorbents have higher $\mathrm{pH}_{\mathrm{zpc}}$ values. For examples, the $\mathrm{pH}_{\mathrm{zpc}}$ of Aspergillus oryzae and Saccharomyces 
cerevisiae were lower than 2 (Westman, 1988), whereas, the $\mathrm{pH}_{\mathrm{zpc}}$ values for iron oxide and aluminum oxide are 5.3 and 9.1, respectively (Park, 1987). From the soil properties one can deduce that the $\mathrm{pH}_{\mathrm{zpc}}$ value of Heilongjiang soil is much lower than that of Jiangxi soil. It was reported that the $\mathrm{pH}_{\mathrm{zpc}}$ of Jiangxi soil was 3.00 (Yuan, 1981) while that of Heilongjiang was less than 2.2 (Xiong and Chen, 1990).

For Jiangxi soil, the effect of $\mathrm{pH}$ values on adsorption of REEs was more complicated than that of Heilongjiang soil. It varied from one organic acid to another. For acetic acid the adsorption of REEs increased with increasing $\mathrm{pH}$, no matter what concentrations of REEs were added. For tartaric acid, there was a plateau for the adsorption of REEs over a range of $\mathrm{pH} 2-6$, and then a rapid increase occurred from $\mathrm{pH} 6$ to $\mathrm{pH}$ 7. For malic and citric acids, the adsorption of REEs decreased first with $\mathrm{pH}$ increasing from 2.5 to 4.5 , then there was no further change or increased slightly when $\mathrm{pH}$ value exceeded 4.5 (Fig. 3). These phenomena might be due to the relatively high amount of ferric oxide and alumina, and relatively high value of $\mathrm{pH}_{\mathrm{zpc}}$ of Jiangxi soil. When the soil $\mathrm{pH}$ below 5.2, reaction (1) may occur. Furthermore, when the soil $\mathrm{pH}$ below 3.2, reaction (2) would be happen, thus resulting in the formation of positivecharge ligand of $\mathrm{Al}(\mathrm{OH})_{2}^{+}$and $\mathrm{Fe}(\mathrm{OH})_{2}^{+}$on the soil surface (Zhu, 1983)

$$
\begin{aligned}
& \mathrm{Al}(\mathrm{OH})_{3} \rightarrow \mathrm{Al}(\mathrm{OH})_{2}^{+}+\mathrm{OH}^{-} \\
& \mathrm{Fe}(\mathrm{OH})_{3} \rightarrow \mathrm{Fe}(\mathrm{OH})_{2}^{+}+\mathrm{OH}^{-}
\end{aligned}
$$

The lower $\mathrm{pH}$ was, the more positive charge had. When the soil surfaces are positively charged, adsorption of strong organic ligand ions may lead to charge reversals. Such charge reversals could enhance adsorption of metal ions. Positive-charged surfaces could adsorb ligands ions or negative-charged REE-organic complexes, then increased REE adsorption. However, there is no more precise information about Jiangxi soil available, this is just our speculation.

\subsection{Effect of organic ligands and $p H$ on extractable REEs from soils}

Effect of organic ligands and $\mathrm{pH}$ on REE desorption from Heilongjiang, Zhejiang, Guangdong and Jiangxi soil is shown in Fig. 4. As can be seen clearly that over the experimental $\mathrm{pH}$ range, almost no REEs can be extracted by $\mathrm{NO}_{3}^{-}$or acetic acid except for Jiangxi soil. However, in the presence of other organic acids, desorption behavior of each REEs was different from different soils. Almost all REEs followed the following release order: Jiangxi $>$ Guangdong $>$ Zhejiang $>$ Heilongjiang soils. This difference is consisted with CEC of these soils. For Heilongjiang, Zhejiang and Guang- dong soils, in the presence of citric, malic and tartaric acids, desorption of REEs decreased with increasing $\mathrm{pH}$ values, so it did for Jiangxi soil in the presence of $\mathrm{NO}_{3}^{-}$, acetic acid and tartaric acid. A similar phenomenon was also reported for other metal ions such as $\mathrm{Cu}^{2+}$ (Padmanabham, 1983), $\mathrm{Cd}^{2+}$ (Gray et al., 1998) and $\mathrm{Zn}^{2+}$ (Pardo and Guadalix, 1996). It is generally recognized that $\mathrm{pH}$ can affect desorption of heavy metal from two aspects. On one hand, it changed the affinity of soils for REEs due to $\mathrm{pH}$-dependent surface-charge density on soil colloids (Cao et al., 2001), leading to the less desorption of heavy metals with increasing $\mathrm{pH}$ value. On the other hand, $\mathrm{pH}$ changes the species of organic ligands, which affect the REE desorption further. Because different organic acid has different $\mathrm{p} K_{\mathrm{a}}$ (Table 3), the concentrations of organic ligand ions should be different at a given $\mathrm{pH}$. The order of $\mathrm{pH}$ for $10^{-2} \mathrm{~mol} / \mathrm{L}$ organic acid solutions was: tartaric acid $<$ citric acid $<$ malic acid $<$ acetic acid. If $\mathrm{pH}$ was the main factor responsible for the release of REEs from soils, at a given $\mathrm{pH}$ condition, relatively high amounts of organic ligands ions should be exist in the presence of tartaric acid, thus resulting high amount of REEs desorption. However, this phenomenon was not observed. Instead, a trend was observed in desorption of REEs from soils in the order of: citric acid $>$ malic acid $>$ tartaric acid $>$ acetic acid, which was consistent with the order of the complex stability of the organic acids with REEs. This indicated that organic acids are the main controlling factor that influenced the REE desorption.

For Jiangxi soil, in the presence of citric and malic acids, desorption behavior of REEs appeared to be quite different (Fig. 4d). No desorption decrement, and even slight increase was found when $\mathrm{pH}$ increased from 3.5 to 6.5. Desorption of REEs dropped down with further increasing $\mathrm{pH}$ value. As mentioned before, there was a competitive reaction for REEs with soil adsorption sites and/or with aqueous organic ligands. The affinity between Jiangxi soil and REEs was lower than those of other soils because of the lower $\mathrm{pH}, \mathrm{CEC}$ and organic matter of Jiangxi soil (Table 1), thus resulting in a lower REE adsorption capacity of Jiangxi soil. In the meantime, the affinity between citric or malic ligands was higher than that of acetic or tartaric ligands. On one hand, when $\mathrm{pH}$ increased, the affinity of soils for REEs increased, thus the desorption of REEs decreased consequently. On the other hand, with the $\mathrm{pH}$ increasing, the species of organic ligand ions increased, leading to the increase in desorption of REEs which effect is prevailing over, which can determine the desorption of REEs. Since the CEC of Heilongjiang, Guangdong and Zhejiang soils were relatively high, the effect of $\mathrm{pH}$ on the desorption decrement was predominant in the presence of citric or malic acid. Similarly, the stability of REE-organic acid complexes is relatively low in the presence of acetic acid or tartaric acid. However, for 

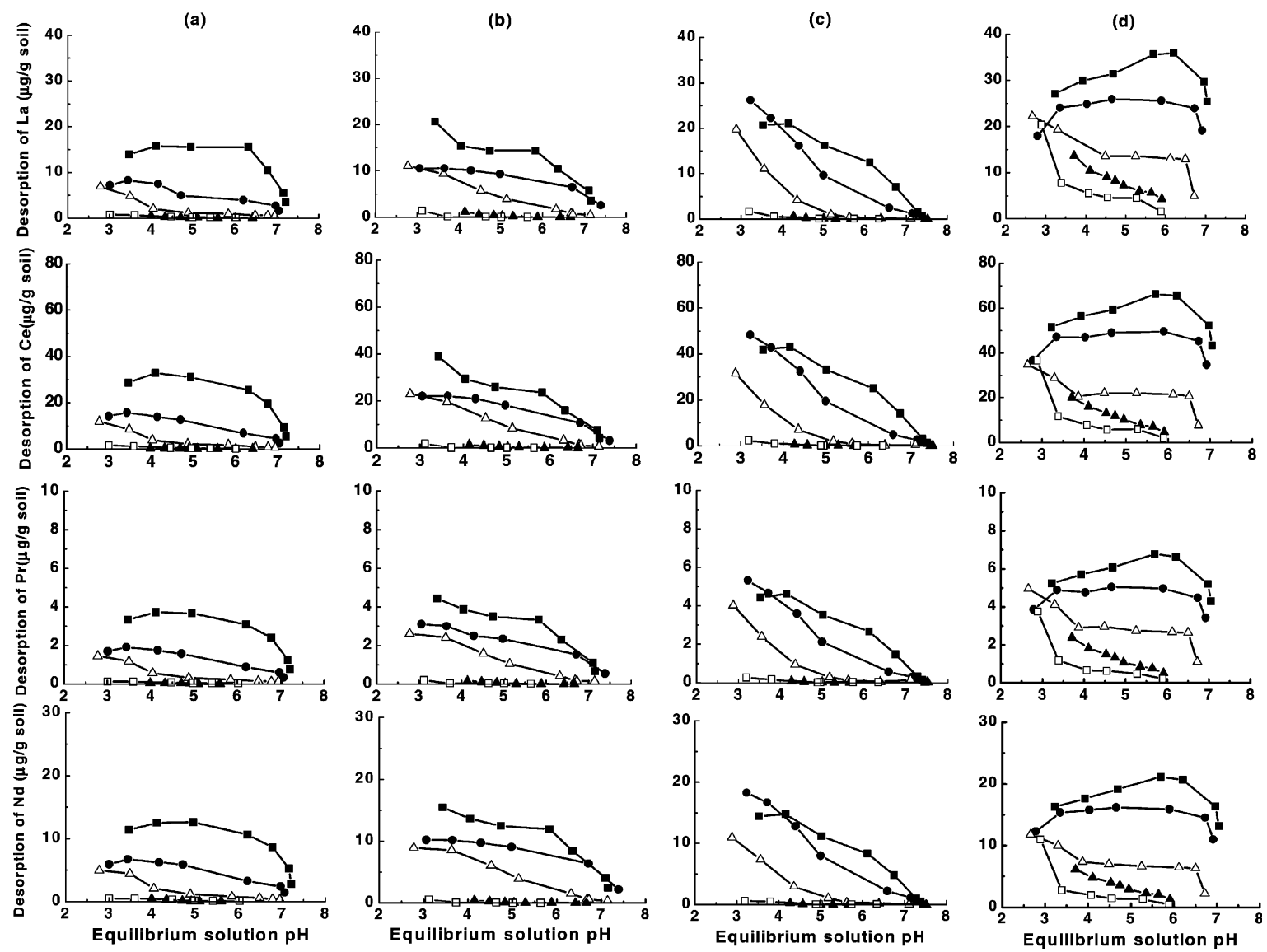

Fig. 4. Effect of organic ligands and pH on desorption of REEs from soils (a) Heilongjiang; (b) Zhejiang; (c) Guangdong; (d) Jiangxi, organic acids: citric acid $(\mathbf{\square})$; malic acid $(\bullet)$; tartaric acid $(\triangle)$; acetic acid $(\mathbf{\Delta})$; nitrate $(\square)$.

Table 3

Low molecular weight organic acids used in this study

\begin{tabular}{llll}
\hline Organic acid & Formula & Ligand form & $\mathrm{p} K_{\mathrm{a}}^{\mathrm{a}}$ \\
\hline Acetic acid & $\mathrm{CH}_{3} \mathrm{CO}_{2} \mathrm{H}$ & $\mathrm{HL}$ & 4.76 \\
Citric acid & $\mathrm{HO}_{2} \mathrm{CCH}=\mathrm{C}\left(\mathrm{CO}_{2} \mathrm{H}\right)(\mathrm{OH}) \mathrm{CH}_{2} \mathrm{CO}_{2}$ & $\mathrm{H}_{3} \mathrm{~L}$ & $3.13,4.78,6.43$ \\
Malic acid & $\mathrm{HO}_{2} \mathrm{CCH}_{2} \mathrm{CH}(\mathrm{OH}) \mathrm{CO}_{2} \mathrm{H}$ & $\mathrm{H}_{2} \mathrm{~L}$ & $3.46,5.10$ \\
Tartaric acid & $\mathrm{HO}_{2} \mathrm{CCH}(\mathrm{OH}) \mathrm{CH}(\mathrm{OH}) \mathrm{CO}_{2} \mathrm{H}$ & $\mathrm{H}_{2} \mathrm{~L}$ & $3.03,4.46$ \\
\hline
\end{tabular}

${ }^{\mathrm{a}} \mathrm{p} K_{\mathrm{a}}$ values were adopted from Serjeant and Dempsey (1979).

Jiangxi soil in the presence of citric or malic acid, a complex reaction can take place with REEs strongly, the effect of $\mathrm{pH}$ on the REE desorption due to increase in soil positive charge was not significant. Under the higher $\mathrm{pH}$ conditions organic ligand ions increased in the equilibrium solution the desorption of REEs increased. The functions of these two reactions are opposite each other. However, none of these reactions predominated and the integrated action of these reactions resulted in desorption of REEs remained unchanged at the $\mathrm{pH}$ range of 3.5-6.5. With $\mathrm{pH}$ further increasing, more and more positive hydroxyl REEs, such as $\operatorname{REE}(\mathrm{OH})^{2+}$,
$\mathrm{REE}_{3}(\mathrm{OH})_{4}^{5+}$ and $\mathrm{REE}_{2}(\mathrm{OH})_{3}^{3+}$ (Ran and Liu, 1992), would adsorb on the negative surface, which caused reduction of the desorption of REEs obviously.

Based on effect of organic ligand concentration on desorption one can obtain the same conclusion that at any $\mathrm{pH}$ investigated there was no exception, i.e., desorption of REEs increased with increasing concentrations of organic acids, which meant that competition reactions between soil surfaces and organic acids more favored organic acids by formation of complex in aqueous solution. Therefore, organic acid was responsible for the REE desorption (Fig. 5). 

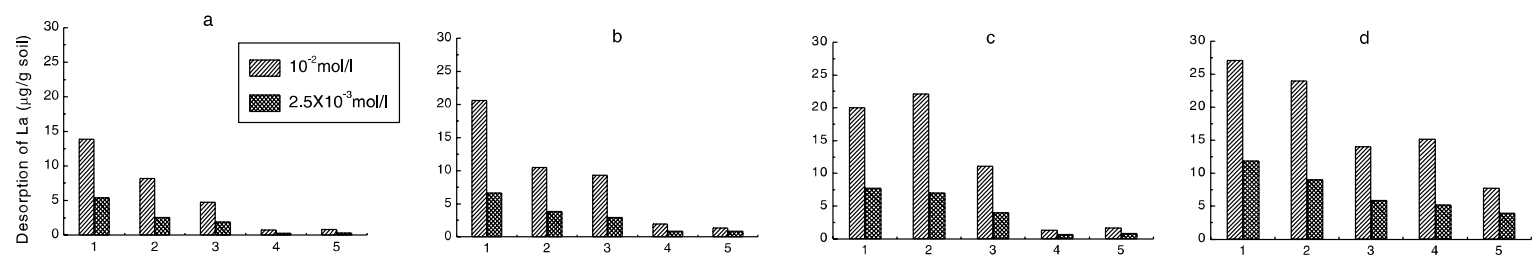

Equilibrium solution $\mathrm{pH}=3.2$
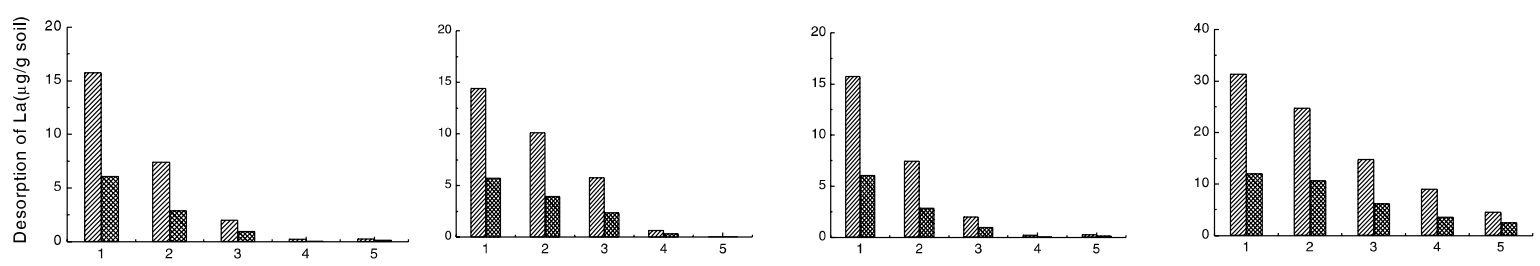

Equilibrium solution $\mathrm{pH}=4.3$
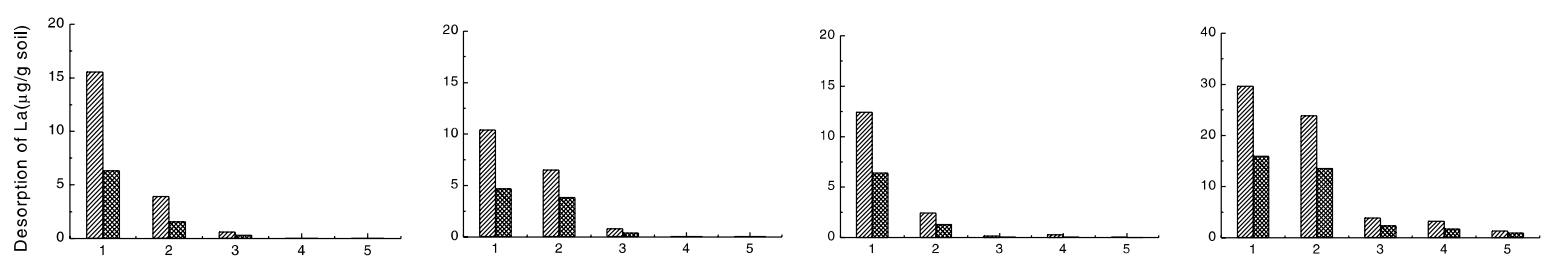

Equilibrium solution $\mathrm{pH}=6.5$

Fig. 5. Effect of different concentrations of organic acids on desorption of REEs at different pH: (a) Heilongjiang soil; (b) Zhejiang soil; (c) Guangdong soil; (d) Jiangxi soil and (1) citric acid; (2) malic acid; (3) tartaric acid; (4) acetic acid; (5) nitrate.

\section{Conclusion}

Based on the above data obtained under the experimental conditions specified, it could be inferred that the adsorption and desorption of REEs were affected by soil $\mathrm{pH}$, and LMWOAs as well. $\mathrm{pH}$ is an important factor affecting the adsorption and desorption of REE in soils as it can change the affinity of sorption sites for REEs and the species of organic acids. However, adsorption by and desorption of REEs from soils were closely relevant to the stability constants of complexes formed between REEs and LMWOAs. In addition, physicochemical properties of soils such as CEC, organic matter, iron-, manganese- and aluminum-oxides also affect the adsorption and desorption behavior of REEs. The information about the adsorption and desorption of REEs in the presence of LMWOAs can mimic the interactions taking place in the rhizosphere soil, and it can also provide a clue to the study on the bioavailability of REEs.

\section{Acknowledgements}

This work was financially supported by the National Natural Science Foundation of China (No. 29890280-
1(2)) and Research Center for Eco-Environmental Sciences (No. K1P-9901).

\section{References}

Anderson, T.A., Guthrie, E.A., Walton, B.T., 1993. Bioremediation (review). Environ. Sci. Technol. 27, 2630-2636.

Backes, C.A., McLaren, R.G., Rate, A.W., Swift, R.S., 1995. Kinetics of cadmium and cobalt desorption from iron and manganese oxides. Soil Sci. Soc. Am. J. 59, 778-785.

Bremmer, W., 1994. Rare earth applications in Chinese agriculture elements. Rare Earths Specialty Metals and Applied Technology 3, 20-24.

Brown, P.H., Rathjen, A.H., Graham, R.D., Tribe, D.E., 1990. Rare earth elements in biological systems. In: Gschneidner Jr., K.A., Eyring, L. (Eds.), Handbook on the Physical and Chemical of Rare Earths. Elsevier, Amsterdam, pp. 423-452.

Bruemmer, G.W., Gerth, J., Tiller, K.G., 1988. Reaction kinetics of the adsorption and desorption of nickel, zinc, and cadmium by goethite. I. Adsorption and diffusion of metals. J. Soil Sci. 39, 37-52.

Cao, X.D., Chen, Y., Wang, X.R., Deng, X.H., 2001. Effects of redox potential and $\mathrm{pH}$ value on the release of rare earth elements from soil. Chemosphere 44, 655-661.

Dalang, F., Stumm, W., 1976. Comparison of the adsorption of hydrous oxide surfaces of aquo metal ions with that of inert complex cations. In: Kerker, M. (Ed.), Colloid and Interface 
Science. vol. IV. Academic Press Inc., New York, pp. 157163.

Elliott, H.A., Denneny, C.M., 1982. Soil adsorption of cadmium from solutions containing organic ligands. J. Environ. Qual. 11, 658-663.

Elliott, H.A., Huang, C.P., 1979. The adsorption characteristics of $\mathrm{Cu}(\mathrm{II})$ in the presence of chelating agents. J. Colloid Interface Sci. 70, 29-45.

Gray, C.W., Mclaren, R.G., Roberts, A.H.C., Condron, L.M., 1998. Sorption and desorption of cadmium from some New Zealand soils: effect of $\mathrm{pH}$ and contact time. Aust. J. Soil Res. 36, 199-216.

Harter, R.D., 1983. Effect of soil pH on the sorption of lead, copper, zinc, and nickel. Soil Sci. Soc. Am. J. 47, 47-51.

Hogg, D.S., McLaren, R.G., Swift, R.S., 1993. Desorption of copper from some New Zealand soils. Soil Sci. Soc. Am. J. 57, 361-366.

Jones, D.L., 1997. Trivalent metal (Cr, Y, Rh, La, Pr, Gd) sorption in two acid soils and its consequences for bioremediation. Eur. J. Soil Sci. 48, 697-702.

Krishnamurti, G.S.R., Cieslinski, G., Huang, P.M., Van Rees, K.C.J., 1997. Kinetics of cadmium release from soils as influenced by organic acids: Implication in cadmium availability. J. Environ. Qual. 26, 271-277.

Li, D.C., Huang, S.B., Wang, W.H., Peng, A., 2001. Study on the kinetics of cerium(III) adsorption-desorption on different soils of China. Chemosphere 44, 663-669.

Li, F.L., Shan, X.Q., Zhang, T.H., Zhang, S.Z., 1998. Evaluation of plant availability of rare earth elements in soils by chemical fractionation and multiple regression analysis. Environ. Pollut. 102, 269-277.

Martell, A.E., Smith, R.M., 1977. Critical Stability Constants: Other Organic Ligands, vol. 3. Plenum Press, New York.

McKeague, J.A., Day, J.H., 1966. Dithionite- and oxalateextractable $\mathrm{Fe}$ and $\mathrm{Al}$ as aids in differentiating various classes of soils. Can. J. Soil Sci. 46, 13-22.

Naidu, R., Harter, R.D., 1998. Effect of different organic ligands on cadmium sorption by and extractability from soils. Soil Sci. Soc. Am. J. 62, 644-650.

Nelson, D.W., Sommers, L.E., 1982. Total carbon, organic carbon, and organic matter. In: Page, A.L. (Ed.), Methods of Soil Analysis, second ed. Part 2. Chemical and Microbiological Properties. American Society of Agronomy, Madison, WI, pp. 539-579.

Padmanabham, M., 1983. Adsorption-desorption behaviour of copper (II) at the goethite-solution interface. Aust. J. Soil Res. 21, 309-320.

Pardo, M.T., Guadalix, M.E., 1996. Zinc sorpiton-desorption by two Andepts: effect of $\mathrm{pH}$ and support medium. Euro. J. Soil Sci. 47, 257-263.

Park, S.W., 1987. Specific chemical reactions at the cadmium, sulfide water interface. Ph.D. disseration, Dep. Civil Eng., Univ. Del., Newark, Del.

Ran, Y., Liu, Z., 1992. Investigation of the mechanism of rare earth elements adsorbed by soils and synthetic oxides. KeXue TongBao 18, 1705-1709.

Ran, Y., Liu, Z., 1993. Adsorption and desorption of rare earth elements on soils and synthetic oxides. Huanjing Kexue Xuebao 13, 288-294.
Rhoades, J.D., 1982. Cation-exchange capacity. In: Page, A.L. (Ed.), Methods of Soil Analysis, second ed. Part 2. Chemical and Microbiological Properties. American Society of Agronomy, Madison, WI, p. 149.

Robert, M., Berthelin, J., 1994. Role of biological factors in soil mineral weathering. In: Huang, P.M., Schnitzer, M. (Eds.), Interaction of Soil Minerals with Natural Organics and Microbes. S.S.S.A. Special. Publ. 17. S.S.S.A., Madison, WI, pp. 29-58.

Serjeant, E.P., Dempsey, B., 1979. Ionisation Constants of Organic Acids in Aqueous Solutions. Pergamon, Oxford.

Shuman, L.M., 1982. Separating soil iron- and manganeseoxide fractions for microelement analysis. Soil Sci. Soc. Am. J. 46, 1099-1102.

Stevenson, F.J., 1994. Humus Chemistry Genesis, Composition, Reactions. John Wiley \& Sons Inc., New York.

Stevenson, F.J., Fitch, A., 1994. Chemistry of complexation of metal ions with soil solution organics. In: Huang, P.M., Schnitzer, M. (Eds.), Interaction of Soil Minerals with Natural Organics and Microbes. S.S.S.A. Special. Publ. 17. S.S.S.A., Madison, WI, pp. 29-58.

Tiller, K.G., Nayyar, V.K., Clayton, P.M., 1979. Specific and non-specific sorption of $\mathrm{Cd}$ by soil clays as influenced by zinc and calcium. Aust. J. Soil Res. 17, 17-28.

Tu, Q., Wang, X.R., Tian, L.Q., Dai, L.M., 1994. Bioaccumulation of the rare earth elements lanthanum, gadolinium and yttrium in carp (Cyprinus carpio). Environ. Pollut. 85, 345350.

Volokh, A.A., Gorbunov, A.V., Gundorina, S.F., Revich, B.A., Frontasyeva, M.V., Chen, S.P., 1990. Phosphorus fertilizer production as a source of rare earth elements pollution of the environment. Sci. Total Environ. 95, 141148.

Wang, J.M., Huang, C.P., Allen, H.E., 2000. Surface physicalchemical characteristics of sludge particulates. Water Environ. Res. 72, 545-553.

Wang, Z.W., Shan, X.Q., Zhang, S.Z., 2001. Comparison of speciation and bioavailability of rare earth elements between wet rhizosphere soil and air-dried bulk soil. Anal. Chim. Acta 441, 147-156.

Wen, B., Shan, X.Q., Xu, S.G., 1999. Preconcentration of ultratrace rare earth elements in seawater with 8-hydroxyquinoline immobilized polyacrylonitrile hollow fiber membrane for determination by inductively coupled plasma mass spectrometry. Analyst 124, 621-626.

Westman, D.C., 1988. Removal of Cadmium (II) from water by Fungi. Master thesis, Dep. Civil Eng., Univ. Del., Newark, Del.

Xiong, Y., Chen, J.F., 1990. Soil Colloids Part 2, Characteristics of soil colloids. China Science Press, Beijing.

Yuan, Z.L., 1981. Primary study of zero point of charge (ZPC) of several kinds of soil colloids. Turang Xuebao 18, 345352.

Zhang, S.Z., Shan, X.Q., Li, F.L., 2000. Low-molecularweight-organic-acids as extractant to predict plant bioavailability of rare earth elements. Intern. J. Environ. Anal. Chem. 76, 283-294.

Zhu, Z.X., 1983. Agrology. China Agriculture Press, Beijing. 